\title{
Sexual Variations of Femoral Neck-Shaft Angle in the Population of Odisha
}

\author{
Rajeev Kumar Kanchan¹, Sonali Subhadarsini², Dharma Niranjan Mishra³, Chinmayi Mohapatra ${ }^{4}$ \\ ${ }^{1}$ Department of Anatomy, B. N. Mandal University, Madhepura, Bihar, India. 2,3,4 Department of Anatomy, \\ Sriram Chandra Bhanja Medical College, Cuttack Under Utkal University Vanivihar, Odisha, India.
}

\section{ABSTRACT}

\section{BACKGROUND}

The peculiar waddling gait of a female attracts most of the anatomists to measure and compare the neck-shaft angle (NSA) of the femora. The femoral neck shaft angle is greater in women due to greater pelvic breadth and shorter femur. Neck-shaft angle was measured by the angle that the neck makes with the shaft of the femur and it is measured on the ventral surface of femur taking the long axis of femoral neck with the long axis of the proximal end of the femur. It gives information about the race it belongs to and normally measures $120^{\circ}$ to $140^{\circ}$. The intention of this study was to establish the femoral neck shaft angle variations in adult male and female for medico-legal and anthropometric studies.

\section{METHODS}

This cross-sectional study was conducted on 84 adult human femora of unknown sex in the anatomy department, Sriram Chandra Bhanja (SCB) Medical College, Cuttack, Odisha, from May 2018 to April 2019. We included all the femora which were free of damage or deformity and fully ossified indicating adult bone. Femora with any pathological changes i.e., cortical bone deterioration, extreme osteophyte activity, osteoarthritis and fracture etc. were excluded from the study. The NSA was measured by protractor and goniometer.

\section{RESULTS}

In the present study the NSA range for the right femur of male was $108^{\circ}-135^{\circ}$ and for the right femur of females $117^{\circ}-135^{\circ}$. The left male femur was $118^{\circ}-135^{\circ}$ and the left female femur was $120^{\circ}-135^{\circ}$. The mean neck shaft angle of male femora was $125.9^{\circ}$ and the female femora was $125.7^{\circ}$. These measurements show that the values were more in males than the females. The value of the present study was statistically significant between male and female i.e., $\mathrm{P}<0.0001$.

\section{CONCLUSIONS}

These measurements are important in the medico-legal cases, reconstructive orthopaedic surgeries, hip replacement surgeries and also while constructing suitable prosthesis. This will also be helpful in the detection of sex by anatomists and forensic experts.

\section{KEY WORDS}

Neck Shaft Angle, Medico-Legal, Anthropometry and Goniometer
Corresponding Author:

Dr. Dharma Niranjan Mishra, Associate Professor of Anatomy

S C B Medical College Cuttack,

Odisha, India.

E-mail: dharmaniranjan.mishra08@gmail.com

DOI: $10.14260 / j e m d s / 2021 / 293$

How to Cite This Article:

Kanchan RK, Subhadarsini S, Mishra DN, et al. Sexual variations of femoral neck-shaft angle in the population of Odisha. J Evolution Med Dent Sci 2021;10(19): 1387-1390, DOI:

10.14260/jemds/2021/293

Submission 28-12-2020,

Peer Review 08-03-2021,

Acceptance 16-03-2021,

Published 10-05-2021.

Copyright (C) 2021 Rajeev Kumar Kanchan et al. This is an open access article distributed under Creative Commons Attribution License [Attribution 4.0 International (CC BY 4.0)] 


\section{BACKGROUND}

The sex determination is almost accurate if the entire skeleton is studied in detail. In the medico-legal cases mostly the isolated long bones and their fragments are studied to determine the sex of the deceased. ${ }^{1}$ The determination of sex from unidentified human skeletal remains is a challenge for Anthropologists and forensic investigators. ${ }^{2}$ Skull and pelvis are usually studied for sex determination. ${ }^{3,4}$ The femur remains the most reliable skeletal region in establishing sex. It is the largest, heaviest, and strongest bone of the human body. ${ }^{5,6}$

So, it takes more time to decay in comparison to the other bones, hence it is a better specimen for sex determination of a human being. The sex differences seen between the males and the females by the Anthropometric study of the bones of the body including soft tissues, explained by Stanfield's Postulation in Evolutionary Biology (1977), which states that the genotypic variations are inversely proportional to the stabilizing selection which explains the morphological difference of adult males and females.

According to Krogman $(1962)^{3}$ the sex identification was $100 \%$ based on the complete skeleton analysis along with skull and pelvis $98 \%$, pelvis alone $95 \%$, only skull bones 90 $\%$, long bone constitutes 80 percent. Later on, he estimated to reduce the above figures by $5-10 \%$ as per the specimen obtained for sex determination. The authors have worked on the sex determination of the bones using the various parameters.

Determination of sex from the available skeleton is very much important in forensic medicine. In medico-legal cases determination of stature, sex, and age from skeletal remains of deceased person is essential. ${ }^{7}$ It is often helpful to the Anatomist and other professionals in the field of Anthropology. 89,10

Sexual dimorphism of the femur has been very well studied in different populations with diverse and interesting results. Much work has been done earlier by various workers like Parson (1914), ${ }^{11}$ Pons (1955), ${ }^{12}$ Lofgren (1956), ${ }^{3}$ Krogman (1986). 6 Hence the long bones are taken for morphological analysis with statistical value to determine sex. ${ }^{13}$

The oblique femoral alignment approximates the feet together under the line of the body weight in standing and walking. It is involved in forward movements also. The peculiar waddling gait of a female attracts most of the anatomists to measure and compare the NSA angle of femora. Femur is more oblique in women due to relatively short femur and wide pelvis. ${ }^{3}$

Hence femurs among the long bones are useful for determination of stature and estimation of sex. Since the accuracy of sexual dimorphism of femur is determined by many parameters, we have taken the femoral neck shaft angle as a preliminary study. The study was conducted on 84 dry human femora of unknown sex. The definite value of neckshaft angle for males and females with statistical significance were compared with other workers.

The present work is an attempt to establish the femoral neck shaft angle variations in adult male and female for medico-legal purpose and Anthropometric studies.

\section{METHODS}

\section{Neck Shaft Angle}

The cross-sectional study was a simple random sampling considering femora of unknown sex in the anatomy department, SCB Medical College, Cuttack, and Odisha from May 2018 to April 2019. NSA is also called an inclination angle. It was measured by an angle that the neck makes with the shaft of femur and it was obtained from the ventral surface of femur as an obtuse angle between the long axis of neck and the proximal end of the shaft of femur. Axis of the neck of the femur was determined by a thread which divides the ventral surface of the neck in two equal halves. So also, the femoral shaft axis was determined by a thread which extends in the mid sagittal plane over the front of the upper end of the femur. Measurement was taken with the help of a protractor in degrees.

\section{Inclusion Criteria}

All the femora were free of damage or deformity and fully ossified indicating adult bone.

\section{Exclusion Criteria}

Femur with any pathological changes (i.e., cortical bone deterioration, extreme Osteophyte activity, Osteoarthritis and fracture etc. was excluded from the study.

\section{Ethical Clearance}

The present work obtained clearance from the Institutional Ethics Committee, S C B Medical College Cuttack, 753007, Odisha as per the principles of World Medical Association Declaration of Helsinki.

\section{Statistical Analysis}

The destructive was followed to analyse mean, standard deviation and $P$ value with level of significance $<0.0001$

\section{RESULTS}

Observations were made in 84 dry, complete, undamaged human femora collected from the Anatomy Department, S.C.B. Medical College and Hospital, Cuttack, Odisha. From each femur above mentioned data were recorded and the details were obtained about the mean, Standard Deviation, percentage, $\mathrm{P}$-value as per the following tables.

\begin{tabular}{|ccccc|}
\hline Parameters & \multicolumn{2}{c}{ Male $\mathbf{( N = 4 5 )}$} & \multicolumn{2}{c|}{ Female (N = 39) } \\
Side & $\begin{array}{c}\text { Value of right } \\
\text { femora } \\
\text { (in degree) } \\
\mathrm{N}=23\end{array}$ & $\begin{array}{c}\text { Value of left } \\
\text { femora } \\
\text { (in degree) } \\
\mathrm{N}=22\end{array}$ & $\begin{array}{c}\text { Value of right } \\
\text { femora } \\
\text { (in degree) }\end{array}$ & $\begin{array}{c}\text { Value of left } \\
\text { femora } \\
\text { (in degree) }\end{array}$ \\
Minimum value & 108 & 118 & 114 & $\mathrm{~N}=18$ \\
Maximum value & 137 & 135 & 135 & 137 \\
Mean and SD & $124.869 . \pm 6.831$ & $126.727 \pm 4.881$ & $125.388 \pm 6.11$ & $126.381 \pm 5.2$ \\
t value & \multicolumn{2}{c}{6.114} & \multicolumn{2}{c|}{6.577} \\
\hline \multicolumn{2}{|c|}{ Table 1. Neck Shaft Angle of Male and Female Femora } \\
\hline
\end{tabular}


In Table1 total eighty-four femora were taken, out of which forty-five were males and thirty-nine were females. The forty-five male femora specimens constituted twentythree from the right side and twenty-two from the left side. Similarly, thirty-nine female femora specimens have eighteen from the right side and twenty-one from the left side. The minimum value of the neck shaft angle of twenty-three male right femora was $108^{\circ}$ while the maximum value was $137^{\circ}$ and the mean value was 124.869 . The minimum value of the neck shaft angle of the twenty-two male femora belonging to the left side was 118 while the maximum value was $135^{\circ}$ and the mean was 126.727 . In the female, the minimum value of the neck shaft angle of the right femora was 114 and the maximum value was $135^{\circ}$ with a mean of $125.388^{\circ}$. The minimum value of the neck shaft angle of the left side female femora was $115^{\circ}$, the maximum value was $137^{\circ}$ and the mean value was $126.381^{\circ}$.

\begin{tabular}{|c|c|c|c|c|c|c|}
\hline \multirow{2}{*}{$\begin{array}{c}\text { Angle in } \\
\text { Degree }\end{array}$} & \multicolumn{2}{|c|}{ Male Right Male Left } & \multicolumn{3}{|c|}{ Female RightFemale Left } & \multirow{2}{*}{$\%$} \\
\hline & Femur & Femur & \% & Femur & Femur & \\
\hline $105-110$ & 1 & 0 & $2.22 \%$ & 0 & 0 & $0 \%$ \\
\hline $111-115$ & 1 & 0 & $2.22 \%$ & 1 & 1 & $5.12 \%$ \\
\hline $116-120$ & 6 & 3 & $20 \%$ & 3 & 2 & $12.82 \%$ \\
\hline $121-125$ & 1 & 7 & $\begin{array}{c}17.77 \\
\%\end{array}$ & 6 & 7 & $33.33 \%$ \\
\hline $126-130$ & 11 & 8 & $\begin{array}{c}42.22 \\
\%\end{array}$ & 4 & 8 & $30.76 \%$ \\
\hline $131-135$ & 2 & 4 & $\begin{array}{c}13.33 \\
\%\end{array}$ & 4 & 2 & $15.38 \%$ \\
\hline $136-140$ & 1 & 0 & $2.22 \%$ & 0 & 1 & $2.56 \%$ \\
\hline & $\begin{array}{r}\text { Table } \\
\text { and Fem }\end{array}$ & $\begin{array}{l}\text { Veck } \\
\text { Fem }\end{array}$ & $\begin{array}{l}\text { ft Ang } \\
\text { (Meas }\end{array}$ & $\begin{array}{l}\text { f Femu } \\
\text { ments }\end{array}$ & $\begin{array}{l}\text { ale } \\
\text { yrees) }\end{array}$ & \\
\hline
\end{tabular}

This table shows the neck shaft angle of the head of femur of male femora was mostly within the range of $126-130$ degree constituting $42.22 \%$, followed by 121 - 125 degree constituting $17.77 \%$. The neck shaft angle of femora of females was mostly in the range of 121 - 125 degree constituting $33.33 \%$, followed by 126 - 130 degree constituting $30.76 \%$.

\begin{tabular}{|c|c|c|c|c|}
\hline Sex & \multicolumn{2}{|c|}{ Male $(\mathrm{N}=45)$} & \multicolumn{2}{|c|}{ Female $(\mathrm{N}=39)$} \\
\hline Number & $\begin{array}{c}\text { Value of right } \\
\text { femora } \\
\text { (in degree) } \\
\mathrm{N}=23\end{array}$ & $\begin{array}{l}\text { Value of left } \\
\text { femora } \\
\text { (in degree) } \\
\mathrm{N}=22\end{array}$ & $\begin{array}{c}\text { Value of right } \\
\text { femora } \\
\text { (in degree) } \\
\mathrm{N}=18\end{array}$ & $\begin{array}{c}\text { Value of left } \\
\text { femora } \\
\text { (in degree) } \\
\mathrm{N}=21\end{array}$ \\
\hline Mean & 124.869 & 126.727 & 125.388 & 126.381 \\
\hline S.D. & 6.831 & 4.881 & 6.108 & 5.277 \\
\hline \multicolumn{5}{|l|}{ t value } \\
\hline & 3. Neck Shaf & Ingle of $M a$ & and Female F & nora \\
\hline
\end{tabular}

Table no.3 showed that the mean of the neck shaft angle of twenty-three male right femora was $124.869 \mathrm{~cm}$ while the standard deviation was \pm 6.831 .

The mean of the neck shaft angle of the twenty-two male femora belonging to the left side was 126.727 while the standard deviation was 4.881 . In the female, the mean of the neck shaft angle of the right femora was 125.388 while the standard deviation was \pm 6.108 . The mean of the neck shaft angle of the left side female femora was 126.381 while the standard deviation was \pm 5.277 .

\begin{tabular}{|ccccc|}
\hline Parameter & N & Mean & Std. Dev. & $\begin{array}{c}\text { Std. Error } \\
\text { Mean }\end{array}$ \\
Neck shaft angle & 45 & 125.78 & 5.965 & 0.889 \\
(in degree) & 39 & 125.92 & 5.621 & 0.900 \\
\hline Table 4. Neck Shaft Angle of Eighty-Four & Male and Female Femora \\
\hline
\end{tabular}

In Table no. 4 and 5, Considering Levene's test for Equality of Variance, Significant value of the Neck-shaft angle for the eighty-four femora specimen was greater than 0.05 . This means that the variances for the two groups i.e., male femora and female femora were not equal.

Hence there was a significant difference in the neck-shaft angle of the male and female femora. It was observed that the mean of the neck shaft angle of the male was $125.78^{\circ}$ with a standard deviation of \pm 5.965 , which was significantly different from the mean value of the neck shaft angle of the female femora, was being $125.92^{\circ}$ with a standard deviation of $\pm 5.621 \mathrm{~cm}$.

\section{DISCUSSION}

The Sexual Dimorphism of the Human Bones, Davivongs $(1963)^{14}$ has stated that the male bones are usually more massive and heavier than female counterparts. The features present in femur bone like crests, ridges, tuberosities, line of attachment of muscles and ligaments are more prominent in males. This also applies to the joints and articular surfaces as well.

Williams and Warwicks (Editor-Gray's Anatomy) (39th edition) had explained that anatomists and forensic experts evaluated the sex of the skeletal materials by external observations. Thereafter the sexual dimorphism had been studied by the actual measurements of different bones. But the femur remained as the most reliable bone in establishing sex. In the present study we considered the neck shaft angle (NSA) for sexual dimorphism of femora.

\section{Neck Shaft Angle}

In the present study Neck Shaft angle ranges in males 108 137 and in females 114 - 135 with a Mean Value in males as 125.9 and in females 125.7.14,15

There was no significant difference in the angle between both the sexes as per the study of 0 Reikeras et al. ${ }^{5}$ The Mean Values were being $128.3^{\circ}$ and $127^{\circ}$ for male and female specimens.

Lofgren ${ }^{6}$ also studied the Mean Value of the femoral neckshaft angle. It was $125.1^{\circ}$ in males and $125.2^{\circ}$ in females, which was almost the same in both the sexes.

According to Fischer ${ }^{16}$ the female subjects of the Japanese, French, Negroes, and Egyptians were having greater angles i.e. $127.1^{\circ}$ to $128^{\circ}$ in relation to $124.3^{\circ}$ to $128^{\circ}$ in their male counterparts.

\begin{tabular}{|ccc|}
\hline Population and Study & Male (in ${ }^{\circ}$ ) & Female (in $\left.{ }^{\circ}\right)$ \\
Lofgran et al. 1956 & 125.2 & 125.1 \\
O. Reikeras et al. & 128.3 & 127 \\
\hline Fischer et al. & $124-128$ & $127.1-128$ \\
\hline Present study & 125.9 & 125.7 \\
\hline Table 6. Comparison of Mean Neck Shaft Angle in Males and Females
\end{tabular}

In the present study the maximum neck shaft angle of the male femur was $135^{\circ}$ and female was $137^{\circ}$. The mean value of neck shaft angle was $125.9^{\circ}$ and $125.7^{\circ}$ for males and females respectively. The value was higher in males in comparison to females. The P-value of neck shaft angle in males and females was highly statistically significant. 
The comparison of Neck Shaft Angle in males and females between present study and other studies have been shown in table above.

In the present study Mean Neck Shaft Angle in males was 125.9 and in females was 125.7. In the other studies it varies from $124^{\circ}-128^{\circ}$ in males and in females it was from $125^{\circ}$. $128^{\circ}$. The Mean Neck Shaft Angle in present study was lower than 0 . Reikeras et al. It corresponds with the value seen in Lofgren et al. 6

In Present study the mean neck shaft angle was $125.7^{\circ}$ which is corroborative with other studies that range from 125 - 128. We observed the Mean value of the Neck Shaft Angle lower than 0 . Reikeras et al and similar to that of Lofgren et al.

\section{CONCLUSIONS}

The neck-shaft angle was slightly higher in males. It ranged between $119^{\circ}$ to $136^{\circ}$ in the males and $118^{\circ}$ to $135^{\circ}$ in females. The difference between males and females was statistically significant i.e., $\mathrm{P}<0.0001$. These measurements are important in the medico-legal cases and have a role in the reconstructive orthopaedic surgery, hip replacement surgery and also constructing suitable prosthesis. This will also be helpful in the detection of sex by anatomists and forensic experts.

\section{Limitations}

The age of the bones is not studied due to unavailability of required information.

Data sharing statement provided by the authors is available with the full text of this article at jemds.com.

Financial or other competing interests: None.

Disclosure forms provided by the authors are available with the full text of this article at jemds.com.

\section{REFERENCES}

[1] Gaikwad KR, Nikam VR. Sexual dimorphism in femur. IOSR Journal of Dental and Medical Sciences 2014;13(7):4-9.
[2] Nidugala H, Bhaskar B, Suresh S, et al. Metric assessment of femur using discriminant functional analysis in South Indian population. Int J Anat Res 2013;1(2):29-32.

[3] Krogman WM, Iscan MY. The human skeleton in forensic medicine. Springficald, IL, USA: Charles C Thomas 1986.

[4] Leelavathy N, Rajangam S, Janakiram S, et al. Sexing of the femora. J Anat Soc India 2000;49(1):17-20.

[5] Reikeras 0, Hoiseth A, Reigstad A, et al. Femoral neck angle: a specimen study with special regard to bilateral differences. Acta Orthop Scand 1982;53(5):775-9.

[6] Lofgren L. Some anthropometric-anatomical measurements of the femur of finns from the view point of surgery. Acta chir Scand 1956;110(6):477-84.

[7] Gupta AK. Essentials of forensic medicine and toxicology. $5^{\text {th }}$ edn. 2014: p. 20(10 to 12).

[8] Stewart TD. Identification by the skeletal structures. In: Camps FE, ed. Gradwholl's Legal Medicine. $3^{\text {rd }}$ edn. Chicago: Year Book Medical Publisher 1976:109-35.

[9] Strecker W, Keppler P, Gebhard F, et al. Length and torsion of the lower limb. J Bone Joint Surg Br 1997;79(6):1019-23.

[10] William PL, Warwick R, Dyson M, et al. Gray's anatomy. In: Osteology-femur. 37th edn. Edinburgh: Churchill Livingstone 1989:434-9.

[11] Parsons FG. The character of the english thigh-bone. J Anat Physiol 1914;48(Pt 3):238-67.

[12] Pons J. Sexual diagnosis of isolated bones of the skeleton. Hum Biol 1955;27(1):12-21.

[13] Sembian U, Muhil M, Srimathi T, et al. A study of sexual dimorphism in femora of rural population of South Tamilnadu, India. Journal of Clinical and Diagnostic Research 2012;6(2):163-5.

[14] Dikshit PC. Textbook of forensic medicine and toxicology. $1^{\text {st }}$ edn. Peepee Publishers and Distributors 2007:69(1 to $5)$.

[15] Dittrick J, Suchey JM. Sex determination of prehistoric central california skeleton remains using discriminant analysis of the femur and humerus. Am J Phys Anthropol 1986;70(1):3-9.

[16] Fischer SG, Verlay MR. LeherBuch Der Anthropologic. 1958:7-8. 